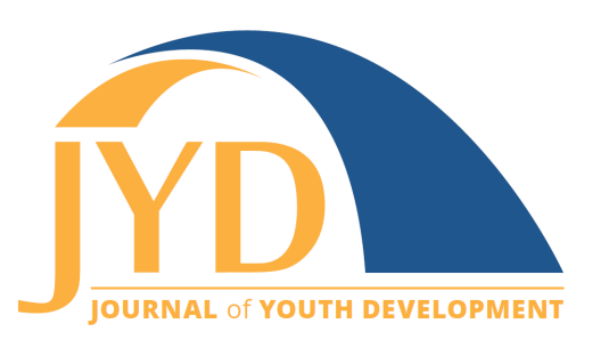

http://jyd.pitt.edu/ | Vol. 16 Issue 5 DOI 10.5195/jyd.2021.1088 | ISSN 2325-4017 (online)

\title{
Seen and Heard: Learning from Young People's Experiences Sharing Power in Faith Communities
}

\section{Jenna Sethi}

Search Institute

jennasethi@gmail.com

\section{Rachel Chamberlain}

Search Institute

rechamber@gmail.com

\section{Clare Eisenberg}

Search Institute

clare@clareeisenberg.com

\section{Eugene Roehlkepartain}

Search Institute

gener@search-insitute.org

\section{Abstract}

Faith communities have been shown to provide a sense of belonging and community while also providing a rich environment for youth to engage and grow as leaders. Yet, few current studies have explored faith communities as spaces for sharing power and sustained youth leadership development. Using a thematic analysis approach, this qualitative study of 222 participants across Jewish, Muslim, and Christian faith communities aimed to explore the role of developmental relationships in young people's lives and their faith and spiritual development. Through the analyses, multiple and varied examples of sharing power emerged, leading us to investigate more fully the roles of leadership, engagement, and participation in young people's experiences in their faith communities. Findings demonstrated that faith communities can provide welcoming, engaging spaces for youth to have voice and develop as leaders. Youth across faith communities experienced authentic opportunities to build and apply leadership skills. These experiences led to positive youth outcomes, including increased confidence, building relational skills, feelings of belonging, and greater engagement. Findings from this study can inform youth development programs more broadly by illuminating concrete ways adults and youth can share power, leading to young people's sense of engagement and belonging.

Key words: youth leadership, youth engagement, sharing power, faith communities, qualitative

(cc) EY New articles in this journal are licensed under a Creative Commons Attribution 4.0 License. This journal is published by the University Library System, University of Pittsburgh and is cosponsored by the University of Pittsburgh Press. The Journal of Youth Development is the official peer-reviewed publication of the National Association of Extension 4-H Youth Development Professionals and the National AfterSchool Association. 


\section{Sharing Power in Faith Communities}

\section{Introduction}

Youth leadership, engagement, and participation are core principles of youth development, providing the foundation for youth and adults to share power. Opportunities for leadership, engagement, and participation often happen in both academic and nonacademic out-of-school time settings. These principles of participation, engagement, and leadership are associated with positive outcomes for youth with a diverse range of backgrounds and identities (Bundick, 2011; Eccles \& Gootman, 2002; Larson, 2000; Mahoney \& Vest, 2012; Marsh \& Kleitman, 2002).

Conceptualizations of leadership, engagement, and participation include program elements and practices that allow youth to experience a sense of competence, purpose, and efficacy (Dawes \& Larson 2011); intrinsic motivation (Anderson \& Sandmann, 2009); clear roles for youth and adults in which all participants understand how their roles fit into the broader structure (Anderson \& Sandmann 2009; Roehlkepartain, 2003); meaningful, scaffolded participation and decision-making opportunities for youth (Benson 1997; Anderson \& Sandmann 2009; Yohalem \& Martin 2007); de-centralized shared power between youth and adults (Anderson \& Sandmann 2009); strong relationships with adult facilitators or staff (Scales \& Roehlkepartain, 2018; Sullivan et al., 2018; Yohalem \& Martin 2007); perception of the staff as both competent and caring (Greene et al., 2013); opportunities to bring their whole selves and share their voices (Derr, 2017); and agency and authority needed to practice leadership authentically (MacNeil, 2006).

When given authentic opportunities to engage and develop leadership skills, youth often experience a variety of positive outcomes including development of strong communication skills and the ability to problem solve, think critically, and clarify their own personal values (Redmond \& Dolan, 2016). Yet, many programs designed to support youth leadership skills encourage youth to think about how they will use these skills in the future rather than encouraging active leadership in the present (Kahn et al., 2009; Mortensen et al., 2014). Hernez-Broome and Hughes (2004) suggest that for authentic youth leadership to happen, young people must have the opportunity to both build skills and apply them in meaningful ways.

There is increasing recognition that an emphasis on skills and opportunities for leadership leaves assumed but unsaid the vital role of relationships as foundational for effective youth leadership skill development and application. Brion-Meisels et al. (2020) describe adult-youth relationships as "the underpinning of effective partnership work" (p. 14) in their book on out-ofschool time programs advancing equity and social change. They continue: "The quality of youth-adult relationships fundamentally shapes the work that adults and youth can do in 
partnership with one another" (p. 15). Thus, belonging, feeling valued, and mutual trust are foundational to youth leadership, engagement, and participation. Search Institute's Developmental Relationships Framework is designed as a resource to address the developmental role of relationships, including their role in leadership development (see Table 1). This is most evident in the framework's "Share Power" element, which focuses on youth and adults experiencing mutual respect and collaboration and invites youth to make decisions and lead (Sullivan et al., 2018).

\section{Table 1: The Developmental Relationships Framework}

\begin{tabular}{|c|c|c|}
\hline Elements & Actions & Definitions \\
\hline \multirow{5}{*}{$\begin{array}{l}\text { Express care: } \\
\text { Show me that I matter } \\
\text { to you. }\end{array}$} & Be dependable & Be someone I can trust. \\
\hline & Listen & Really pay attention when we are together. \\
\hline & Believe in me & Make me feel known and valued. \\
\hline & Be warm & Show me you enjoy being with me. \\
\hline & Encourage & Praise me for my efforts and achievements. \\
\hline \multirow{4}{*}{$\begin{array}{l}\text { Challenge growth: } \\
\text { Push me to keep getting } \\
\text { better. }\end{array}$} & Expect my best & Expect me to live up to my potential. \\
\hline & Stretch & Push me to go further. \\
\hline & Hold me accountable & Insist I take responsibility for my actions. \\
\hline & Reflect on failures & Help me learn from mistakes and setbacks. \\
\hline \multirow{4}{*}{$\begin{array}{l}\text { Provide support: } \\
\text { Help me complete tasks } \\
\text { and achieve goals. }\end{array}$} & Navigate & Guide me through hard situations and systems. \\
\hline & Empower & Build my confidence to take charge of my life. \\
\hline & Advocate & Stand up for me when I need it. \\
\hline & Set boundaries & Put in place limits that keep me on track. \\
\hline \multirow{4}{*}{$\begin{array}{l}\text { Share power: } \\
\text { Treat me with respect } \\
\text { and give me a say. }\end{array}$} & Respect me & Take me seriously and treat me fairly. \\
\hline & Include me & Involve me in decisions that affect me. \\
\hline & Collaborate & Work with me to solve problems and reach goals. \\
\hline & Let me lead & Create opportunities for me to take action and lead. \\
\hline \multirow{3}{*}{$\begin{array}{l}\text { Expand possibilities: } \\
\text { Connect me with people } \\
\text { and places that broaden } \\
\text { my world. }\end{array}$} & Inspire & Inspire me to see possibilities for my future. \\
\hline & Broaden horizons & Expose me to new ideas, experiences, and places. \\
\hline & Connect & Introduce me to people who can help me grow. \\
\hline
\end{tabular}

Note. Relationships are, by definition, bidirectional, with each person giving and receiving. So, each person in a strong relationship both engages in and experiences each of these actions. However, for the purpose of clarity, this framework is expressed from the perspective of one young person. 


\section{Sharing Power in Faith Communities}

Despite studies showing the unique developmental benefits of participation in religious community activities for youth, faith communities often go unnoticed in the youth development field (Larson et al., 2006). These communities, including churches, mosques, synagogues, and temples, have been shown to provide a sense of belonging and community (Mitha \& Adatia, 2016) as well as a rich environment for youth to be engaged and potentially grow as leaders. Faith communities have also provided culturally specific opportunities for youth who were excluded from or marginalized in racially segregated Eurocentric Christian Protestant and Catholic churches that dominated religious youth programming through much of U.S. history (Costello, 2001; Theriault, 2018).

Few current studies have explored faith-based communities as spaces for sharing power and sustained youth leadership development (Garza et al., 2007; Roehlkepartain 2003). The majority of current leadership research has focused on theories of adult leadership in organizations and workplaces, leaving a gap in our understanding of what youth experience when given opportunities to take on leadership roles (MacNeil, 2006; Mortensen et al., 2014). This study aimed to explore the developmental experiences of young people in the context of faith communities. We explore the impact of those experiences in 13 Muslim, Jewish, and Christian faith communities (congregations) in the Midwest and Southeast United States.

Three research questions guided this study:

1. What do faith-based communities do to meaningfully engage young people?

2. What do adults in faith-based communities do to build relationships and share power with young people?

3. How are youth impacted by their experiences with adults who share power in these faith-based communities?

The primary questions in the study focused on the role of developmental relationships in young people's lives and faith and spiritual development. Through these more specific analyses, multiple and varied examples of sharing power emerged, leading us to investigate the roles of leadership, engagement, and participation in young people's experiences in their faith communities. 


\section{Methods}

\section{Participants}

We recruited a diverse group of participants focusing on religious tradition, racial/ethnic identities of members, size of congregation, and geographical location. To recruit participants, we used a snowball sampling technique (Noy, 2008). Through an initial phone interview with each congregation, we established a "point person" or small team to receive a small stipend for their work in recruiting youth, parents, and leaders for focus groups. Demographic and other significant characteristics of congregations are shown in Table 2 and of participants in Table 3.

Table 2: Participating Congregation Information

\begin{tabular}{|c|c|c|c|c|c|}
\hline State & Tradition & Denomination & Size $^{a}$ & Location & Demographics \\
\hline \multirow[t]{8}{*}{ Minnesota } & \multirow[t]{4}{*}{ Christian } & Lutheran & Large & Suburban & mostly White \\
\hline & & Evangelical & Small & Urban & mostly Latino/a/x \\
\hline & & Methodist & Medium & Rural & mostly White \\
\hline & & Catholic & Large & Urban & mostly Latino/a/x \\
\hline & \multirow[t]{2}{*}{ Jewish } & Reform & Medium & Urban & mostly White \\
\hline & & Conservative & Large & Suburban & mostly White \\
\hline & \multirow[t]{2}{*}{ Muslim } & - & Medium & Suburban & $\begin{array}{l}\text { mostly Middle } \\
\text { Eastern }\end{array}$ \\
\hline & & - & Medium & Urban & multi-ethnic \\
\hline \multirow[t]{5}{*}{ North Carolina } & \multirow[t]{4}{*}{ Christian } & Catholic & Large & Urban & mostly White \\
\hline & & Baptist & Medium & Suburban & mostly White \\
\hline & & Presbyterian & Medium & Urban & multi-ethnic \\
\hline & & Baptist & Small & Rural & $\begin{array}{l}\text { mostly } \\
\text { Black/African } \\
\text { American }\end{array}$ \\
\hline & Jewish & Reform & Large & Suburban & mostly White \\
\hline
\end{tabular}

a Small: Average weekend attendance 50 or fewer people, Medium: Average weekend attendance between 51 and 300 people, Large: Average weekend attendance between 301 and 2,000 people 
Journal of Youth Development | http://jyd.pitt.edu/ | Vol. 16 Issue 5 DOI 10.5195/jyd.2021.1088 Sharing Power in Faith Communities

Table 3. Percentage of Participants Within Specified Demographic

\begin{tabular}{|c|c|c|}
\hline \multirow{3}{*}{$\begin{array}{l}\text { Congregation } \\
\text { attended }\end{array}$} & Christian & $64 \%$ \\
\hline & Jewish & $17 \%$ \\
\hline & Muslim & $19 \%$ \\
\hline \multirow{4}{*}{ Role } & Youth (ages 9-19) & $37 \%$ \\
\hline & Parenting adults & $25 \%$ \\
\hline & Congregation leaders & $25 \%$ \\
\hline & Exemplary relationship-builders & $12 \%$ \\
\hline \multirow{6}{*}{ Race/Ethnicity ${ }^{a}$} & White & $40 \%$ \\
\hline & Asian (including East Asian and Middle Eastern) & $7 \%$ \\
\hline & Black/African/African American & $13 \%$ \\
\hline & Latino/a/x/Hispanic & $7 \%$ \\
\hline & Multiracial/other & $5 \%$ \\
\hline & Did not specify & $29 \%$ \\
\hline \multirow{4}{*}{ Gender ${ }^{a}$} & Male & $33 \%$ \\
\hline & Female & $43 \%$ \\
\hline & Nonbinary & $0.50 \%$ \\
\hline & Did not specify & $21 \%$ \\
\hline
\end{tabular}

a Participants had the option to voluntarily report their race/ethnicity and gender. Responses to these open-ended questions were categorized by researchers. For example, responses such as "female," "woman," and "girl" are included in the "Female" category; responses such as "Pakistani," "Asian," and "Middle Eastern" are included in the "Asian" category; responses such as "Jewish" or "mixed race" are included in the "multiracial/other" category.

\section{Data Collection and Analysis}

A team of four researchers developed a set of focus group protocols designed for youth, parenting adults, and congregation leaders to better understand the impactful relationships and experiences for young people in their faith communities. A group of racially and ethnically diverse advisors representing Jewish, Christian, and Muslim communities shared feedback, 


\section{Sharing Power in Faith Communities}

which was then incorporated into the final protocols. The research team who conducted the focus groups included people identifying as Christian and culturally Jewish, White, and Black, and of European and African descent. The majority of focus groups were conducted in English and two focus groups were conducted in Spanish. Onsite in each faith community, researchers conducted 60- to 90-minute focus groups of four to eight participants each. During the focus groups, researchers asked participants a series of semi-structured questions to explore their experiences building relationships and engaging in their faith communities.

Our analysis of the qualitative data used a thematic analysis approach, facilitated by NVivo software (Clarke \& Braun, 2013; Charmaz, 2008). All focus groups and interviews were recorded and transcribed. After developing an initial codebook using NVivo, three researchers separately coded the same focus group transcript from the data set. They then discussed the codebook together, refining coding norms. After the initial coding and codebook refinement process, two researchers coded a set of additional focus group transcripts, again checking for alignment and further refining the codebook. Finally, researchers individually coded the remaining transcripts using the refined codebook. All researchers created memos to document the coding process, emerging themes, and questions (Clarke \& Braun, 2013). After coding focus group data, the research team further refined codes, identifying emerging themes. In total, the team analyzed over 43,000 lines of text.

\section{Findings}

\section{How Adults Engage Youth and Share Power in Faith Communities}

\section{Welcomed, Not Judged}

\section{I feel a good spirit when I walk in the double doors. - Youth Participant}

The stage for sharing power is often set by welcoming young people into a space before they are asked to engage and become leaders. Across faith traditions and congregations, youth said it was important to feel welcomed and not judged. They appreciated feeling seen for who they are, for being themselves, and having their voices heard. Many talked about the importance of "being greeted" and others of introducing themselves if they were new to the congregation. They often used the term "inclusive" to describe the feeling of their congregation. One young person noted, "It's just good to have a place like that, where you always feel safe, and you don't worry about how other people are going to treat you." Youth described their congregations as a "community" or a "family" where adults encouraged them to be involved. 


\section{Sharing Power in Faith Communities}

One young person described the feeling they got at their Masjid, noting: "I love how people are inclusive here, too. Like, you see someone who may be alone, and you want to include them. You'll never find someone alone, because when someone sees them alone, they'll say, 'You want to come talk with us?' That's something I've seen a lot here."

Similarly, leaders and parenting adults who felt connected to their congregation described the overall feeling of the congregation as "inclusive," "supportive," and "like a family." Many felt like it was the first place where others did not judge them. As one leader said, "You hear many times over, 'This is the first place I've been welcome in. "' Some adults said they knew they could count on others in their congregations in times of need.

Some parenting adults and leaders explained that their congregations went beyond inclusiveness to actively invite diverse groups of people into the congregation. Many valued building intentional connections in their surrounding communities and interfaith connections with local churches, synagogues, and mosques. They hosted community events, interfaith dialogues, service projects, and other events. Study participants at one congregation described an annual event they host in their neighborhood, giving away thousands of pounds of food and school supplies along with an entertainment show involving youth.

\section{Young People Feel Seen and Heard}

The message is, as a young person, the moment you are born, you are important, and we want you to be seen and heard in this place. - Adult Participant

Having power includes one's voice being heard. Adults who shared power with youth congregants set an example by respecting young people's voices and asking them about their needs. One young person mentioned that the leadership in their congregation "definitely look to youth for youth-related things." Adults and leaders talked about inviting young people to be themselves, learn, and play alongside adults. For example, one congregation used a prayer young people had written in a religious class for their Lenten prayer series. Adults commented on how powerful it was to read aloud together the words youth in their congregation had written. Youth found these invitations to be heard meaningful.

Adults worked to make congregation spaces open and inviting for youth, where they felt they could be seen. One parent noted, "The kids have fun here, you know, the adults aren't sitting here going, 'Shh, you're too loud, stop moving.' . . . They're not getting yelled at by adults and told to sit quiet in a corner, which has happened in other places." Others talked about taking 


\section{Sharing Power in Faith Communities}

time to get to know youth in the congregation and showing them that their presence matters. Youth also appreciated when adults shared power with them by allowing them to choose their level of involvement. As one young person noted about their synagogue, "They always want you to come and be involved, but they respect you if you don't always want to come and do it."

\section{Youth Are Invited to Lead}

It's a cool experience, cause as teens, we get to make our own programs.

\section{- Youth Participant}

In Search Institute's Developmental Relationships Framework, one of the actionable components of sharing power is "let me lead." Youth and adults shared that their congregations provided important and unique spaces for sustained youth leadership development. They reported few other places in young people's lives where they are called on to lead regularly. Across faith communities, young people shared opportunities such as teaching peers and younger children, tutoring (religious education, such as for bar and bat mitzvah preparation), working as camp counselor, leading in worship services (ushering, reading texts, playing music, running audiovisual equipment), designing youth programming and events, sitting on youth councils and congregation councils, coordinating volunteer opportunities, and leading fundraisers and activities for adults and peers.

One adult noted that in their congregation's strategic plan "there's a whole strategy or tactic for [the youth] to be supported and appointed in more leadership roles throughout the church." A young person shared that they were able to play a leadership role in planning a retreat: "Every event is planned by teens, overseen by adults," they said. "But everything's planned by us, which I think is a cool opportunity, 'cause it gets a lot of people involved." Another young person described a large volunteer operation that they had participated in as a child, and how they were now in charge of leading adults: "There are different levels of leadership and being able to be involved."

Many roles youth had opportunities to fill went beyond surface level because they were given power to make decisions that impacted them, they were involved in the planning and operations of the congregation, and they were provided opportunities not only to lead their peers, but to lead adults. These roles, both large and small, made them feel "more engaged," and made it "more interesting" to be part of their congregation. Youth in large congregations, where it was possible to feel lost in the crowd, were especially appreciative of being asked to take leadership roles: "I feel like our church being so massive, they still welcome us, as youth, 


\section{Sharing Power in Faith Communities}

into helping out with the church," one said, "whereas some other more traditional places don't trust high schoolers to do everything right [laughs]."

Adults saw the value of creating leadership roles in engaging youth in their faith communities as well: "I think as the kids get older and lead, they [adults] help them circle back into leadership roles. And that's so valuable, to have that role and then guide others." Others said it was important to show young people that they "have something to contribute."

\section{Intergenerational Relationships Are Foundational}

I talk to people who are 80 or so and I talk to people way younger than me. I talk to everybody; it's like a family! - Youth Participant

Meaningful and reciprocal intergenerational relationships are a foundational piece of sharing power and inviting youth to lead. Youth and adults alike discussed how important it was to them to build relationships across different age groups. Young people talked about shared meals, intergenerational mission or service trips, and all-congregation retreats. One young person talked about the importance of family gatherings supported by their congregation for building relationships, where they were "forming a relationship with everybody, still learning, but having fun."

Another young person talked about the importance of their chavurah, a close-knit group of family friends in their synagogue: "We went on an Israel trip together, and that was a really cool bonding experience. I got to bond with the parents and the grandparents and the kids." Young people appreciated the importance of celebrating religious holidays with people of different ages. One youth participant explained how their family came to the masjid every day during Ramadan for the Iftar dinner: "I feel like that helps me build relationships, 'cause it's 30 days, and I try to come here every day. I meet a lot of new people . . . like everyone comes here and it helps build on those connections."

Adults also described their congregations as some of the only spaces in which they participated in activities and events with multiple generations. Most prominently, adults mentioned volunteering and religious education (including Sunday school, confirmation, vacation Bible school, and Bible study) as places where they built relationships with people of different ages and backgrounds. Similar to youth participants, adults enjoyed praying together, dinners, sitting together in services, and visiting after services. 
One parenting adult talked about how much they appreciated their church's intergenerational Sunday school where people of all ages were in groups together. Some congregations provided programming beyond worship designed to create space for people to be vulnerable together in small groups and share stories, often across generations. One leader explained, "You really start to hear what people's stories are, and that is, I think, more of what brings this congregation together, is the diversity of the story."

\section{The Impact of Sharing Power with Young People}

\section{It makes me personally want to be here. - Youth Participant}

Through their experiences of shared power, young people across the faith communities developed their sense of self as capable leaders, built stronger relationships, and were inspired to see themselves as an integral part of the community. They felt committed to staying engaged now and in the future.

\section{Developed a Positive Sense of Self as a Capable Leader}

Look at where I am in this now! I'm a youth, but now I'm up there! - Youth Participant

Across faith traditions, youth noted that because of their intergenerational relationships and experiences being invited to lead in their congregations, they had developed a more positive sense of themselves as capable leaders. As one young person noted, "I'm better with leading with a lot of different ages of children, 'cause I've worked with toddlers to 8-year-olds." They talked about gaining confidence and becoming more outgoing. They shared that they believed in themselves more, were proud of their accomplishments, and felt that they had a purpose in life. They became more aware of their own personal gifts and talents. They recognized their resilience and their ability to make it through hard times. They talked about realizing they could stand up for themselves and for others and do things without always relying on their friends to "do the same thing." One young person explained, "I can fight for myself, and I know what I'm capable of." They were more apt to get out their "comfort zone" and felt "more open to new things."

\section{Built Stronger Relationships in the Faith Community}

I've formed relationships with people older than me because I tend to be approached by adults to help with things. - Youth Participant 


\section{Sharing Power in Faith Communities}

Sharing power by welcoming young people, listening to their voices, and inviting them to lead builds trust. The commitment of adults and youth in faith communities to build relationships across ages and experiences led young people to feel they had strong relationships they could count on. Through opportunities like playing music together in worship to volunteering together in the community, experiences that put young people and adults on a level field helped strengthen relationships. One young person noted that intergenerational events at their mosque helped them "build strong relationships and meet new people." Youth participants were also excited that younger children they had taught looked up to them and saw them as leaders and friends.

\section{Inspired to Stay Engaged With the Faith Community Now and in the Future}

It was clear that adults across faith communities prioritized young people's presence in their congregations and hoped they would carry on traditions within them. When they shared power by welcoming youth and inviting them to lead, it inspired youth to want to be more engaged.

One young person shared that an adult and an older peer in the congregation invited them to read Scripture during Mass. They, "showed me how to do it, and then I just did it. [They] literally just pushed me into the deep end to do it, and now I do it literally every Sunday." Now, the participant shared, others reach out to them to learn about how they can get involved in reading Scripture in Mass as well. Youth talked about feeling "more invested" in their faith communities and seeing themselves there in the future because of the strong relationships they had made and the leadership roles they had been offered.

Adults also shared ways they saw young people becoming more engaged. An adult shared that bringing a young person to a religious youth conference was "a turning point for her in her faith and wanting to get more active." Another explained that young people tell them, "I'm active in a faith context because of a particular conversation we had." One adult shared an example of a time they connected with a less-engaged young person about sports. After that exchange, they observed, the young person "started showing up more and taking different interests in what was happening, because I think [they] felt seen."

\section{Discussion}

MacNeil (2006) defined leadership as a "relational process combining ability (knowledge, skills, and talents) with authority (voice, influence, and decision-making power) to positively influence and impact diverse individuals, organizations, and communities" (p. 29). Our findings in these 


\section{Sharing Power in Faith Communities}

13 faith communities suggest that these institutions offer unique and important places for youth to find their voice and develop as leaders within the context of a supportive, sustained, intergenerational community. Youth experienced authentic opportunities to build skills and apply them through teaching, tutoring, leading in worship services, sitting on youth councils, coordinating volunteer opportunities, and leading activities for adults and peers. These experiences led to positive youth outcomes, including increased confidence, building relational skills, feelings of belonging, and greater engagement.

Youth may have unique opportunities to engage and take on leadership roles in faith communities in part because there may be fewer barriers to participation compared to other forms of youth programming. Barber and colleagues (2014) assert that "it is these youth who may gain the most from involvement" (p. 24). Often, faith communities are seen as accessible, convenient, neighborhood-based spaces to deliver services inexpensively. There are often programs and opportunities for youth at every age, and they are able to develop lifelong relationships with others.

Yet, there is a deeper role, rooted in traditions of justice and leadership, that many congregations have historically played in developing community leaders. Congregations have also offered sustained intergenerational community and relationships across decades, lifetimes, and even multiple generations not found in other settings. Faith communities have played significant roles in congregants' lives as the community through which they participate in traditions that shape life's meaning and purpose, find community with like-minded people, and mark most of life's most significant events, such as birth, coming of age, marriage, and death (Gates, 2021).

However, the preceding paragraph cannot be left without caveats. There are also faith communities today where young people (and adults) are marginalized not only by race or ethnicity but by sexual orientation, gender identity, and gender (Armitage \& Dugan, 2006; Dessel et. al., 2017). In some faith communities, traditions of justice, love, and inclusion have been overshadowed by discrimination, inequity, and abuse cloaked in harmful religious doctrine and misuses of religious authority. Faith communities, like other institutions or sectors of society, have significant limitations and serious work to do to live up to their potential and their missions. They also offer unique strengths and capabilities, many of which we saw as we spent time talking with young people, parenting adults, leaders, and relational exemplars in these congregations. 


\section{Sharing Power in Faith Communities}

\section{Implications for Faith Communities}

This study can be seen as both reassuring and challenging for faith communities. On one hand, it reinforces the value of decades, if not centuries, of youth leadership development practices that are woven into the fabric of congregational life. At the same time, some of these practices seem quaint when declines in participation are headlines, and congregations are competing with sports, technology, and other activities for young people's time and attention.

However, based on the experiences of the young people in this study, churches, mosques, synagogues, and other religious communities can offer intergenerational, relational communities that uniquely (though not exclusively) respond to developmental and human needs: the need to be known, to be loved, to matter, and to make a difference.

Of course, all faith communities are not ready and open for that. As we've noted, some congregations and faith traditions have excluded some groups of people or identities. Others may still be reluctant to share power with youth, fearing that they are giving up influence and losing control.

Yet, as we explored in this study, sharing power in the context of a trusting relational community opened up opportunities for young people to meet new challenges, lead, and become more capable of positively contributing to their faith communities. Their leadership did not detract from adult leadership; rather, it enhanced the ability of faith communities to live out their missions, benefitting people of all ages within (and potentially beyond) the congregation. It also sets in motion the potential of ongoing leadership and engagement by young people into the future, which addresses a central concern of many religious leaders today: ongoing leadership in a time of declining religious participation.

It is also important to ask whether the types of leadership opportunities available within faith communities go far enough. Youth are organizing and leading within movements such as Black Lives Matter, March for Our Lives, and climate justice initiatives. Young religious leaders catalyzed the Civil Rights movement and other social change movements throughout history. Given that context and legacy, are faith communities satisfied with defining and confining youth leadership within the bounds of congregational programming? What opportunities are there for these young people to join with others to work for change in areas that matter to them and are also vital to their faith commitment? 


\section{Sharing Power in Faith Communities}

\section{Implications for Community-Based Youth Work}

In addition to reflecting on faith communities themselves, this study surfaces intriguing questions about leadership development and sharing power for consideration in the context of community-based youth development, including programs sponsored by civic and governmental organizations. Transferability is not direct, but comparisons could prompt innovation.

Consider, for example, the many different "levels" of sharing power that take place between youth and adults within the intergenerational community of congregational life and culture. Without necessarily planning it, adults are often scaffolding opportunities by engaging youth at young ages in leadership roles such as helping out with religious education, leading parts in worship, or participating in service activities. As they grow up, they take on roles with more responsibilities, such as leading adults in volunteer activities or teaching their own classes.

From reading a lesson during a worship service to becoming a camp counselor responsible for younger youth, young people had multiple small, medium, and large opportunities to contribute meaningfully and lead. In some cases, they were invited to start new programs that they felt called to lead. Leadership is not a separate program; it is embedded within the people and the activities they are already doing. This reframes leadership as part of the continuum of participation, rather than a separate "track." It seamlessly blends relationship building, program development, and leadership development into a self-generating process.

The second implication for the broader youth development field is to consider what might be learned and gained from more deeply partnering with congregations at the community level. What strengths might these institutions bring to the diverse world of youth development if they were more consistently woven into the fabric of the youth development infrastructure-more than just as host sites for after-school programs?

In a study on the developmental experiences of more than 2,000 eleventh graders in 19 diverse high schools, Larson et al. (2006) found that youth experienced positive developmental experiences in all types of co-curricular and after-school activities more than in the classroom. Compared to the other types of programs studied (sports, arts, and service), youth in religious activities reported higher rates of positive identity, emotional regulation, and interpersonal development. Sports and arts excelled in initiative development, while service was associated with the development of teamwork, positive relationships, and social capital. Our study of leadership development echoes Larson and colleagues' findings, particularly in terms of identity and interpersonal development. If a shared goal and vision across a community is for holistic 


\section{Sharing Power in Faith Communities}

development across all domains of development, it is worth exploring the potential of bridging religious-based and community-based youth work.

Despite differences-some of which have been exacerbated by the politicization of religion in the past 50 years (Balmer, 2007)—faith-based youth workers and community youth workers share numerous priorities for youth work and youth development (Garza et al., 2007). Which core capacities of churches, mosques, synagogues, and temples might be a resource for youth leadership and development? What might be learned from them and with them? What might they learn from others? And, most important, how might those in the community who are dedicated to young people work to ensure that each and every young person has equitable access to opportunities and relationships to support their growth and thriving?

\section{Implications for Future Research}

Faith communities are relatively unexplored spaces for understanding youth development and sharing power. This study reinforces the potential for building well-rounded, sustained, intergenerational relationships that allow adults to mentor and partner with young people as they grow. But we don't know from this qualitative study in 13 congregations how widespread and consistent those opportunities are and which youth they are engaging beyond this sample.

Furthermore, we only know youth and adults' self-perceived descriptions of the impact of these experiences. We don't know from our study whether the same outcomes would surface in other studies using other methods. For example, would we be able to replicate Larson and colleagues' (2006) study which found that faith communities tended to have a particular impact on positive identity, emotional regulation, and interpersonal development? Much more can be learned about those experiences and their long-term impact.

After spending time in over a dozen mosques, synagogues, and churches, we know these congregations represent a wide variety of beliefs, practices, people young and old, and opportunities. Similarly, within the broad mix of an estimated 350,000 congregations (Grammich et al., 2010) across the United States, many faith communities could be learning and action partners for almost any youth development organization, network, or collaborative. Like any organizations, they face their own challenges, and some may be difficult or impossible to work with. Others, however, have rich histories and sophisticated practices for engaging young people-often starting early in childhood-as valued contributors and leaders in their intergenerational communities. Listening, watching, and learning with and from them has the potential to strengthen the whole field. 
Journal of Youth Development | http://jyd.pitt.edu/ | Vol. 16 Issue 5 DOI 10.5195/jyd.2021.1088 Sharing Power in Faith Communities

\section{References}

Anderson, K. S., \& Sandmann, L. (2009). Toward a model of empowering practices in youth-adult partnerships. Journal of Extension, 4オ2), 1-8.

Armitage, J. S., \& Dugan, R. E. (2006). Marginalized experiences of Hispanic females in youth-based religious groups. Journal for the Scientific Study of Religion, 45(2), 217-231. (http://www.jstor.org/stable/3838314)

Balmer, R. (2007). Thy kingdom come: How the religious right distorts faith and threatens America. Basic Books.

Barber, B. L., Abbott, B. D., Neira, C. J. B., \& Eccles, J. S. (2014). Meaningful activity participation and positive youth development. In M. J. Furlong, R. Gilman, E. S. Huebner (Eds.), Handbook of positive psychology in schools (pp. 235-252). Routledge.

Brion-Meisels, G., Fei, J. T., \& Vasudevan, D. S. (2020). At our best: Building youth-adult partnerships in out-of-school time settings. Information Age Publishing.

Bundick, M. J. (2011). Extracurricular activities, positive youth development, and the role of meaningfulness of engagement. Journal of Positive Psychology, 6(1), 57-74. (https://doi.org/10.1080/17439760.2010.536775)

Charmaz, K. (2008). Grounded theory as an emergent method. In S. N. Hesse-Biber \& P. Leavy (Eds.), Handbook of Emergent Methods (pp. 155-172). Guilford Press.

Clarke, V., \& Braun, V. (2013). Teaching thematic analysis: Overcoming challenges and developing strategies for effective learning. The Psychologist, 26(2), 120-123.

Costello J., Toles M., Spielberger J., \& Wynn J. (2001). How history, ideology, and structure shape the organizations that shape youth. In P. L. Benson \& K. J. Pittman (Eds.) Trends in youth development (Outreach Scholarship, vol. 6), (pp. 191-229). Springer. (https://doi.org/10.1007/978-1-4615-1459-6_7)

Dawes, N. P., \& Larson, R. (2011). How youth get engaged: Grounded-theory research on motivational development in organized youth programs. Developmental Psychology, 471), 259-269.

Derr, V. (2017). Participation as a supportive framework for cultural inclusion and environmental justice. Revista Internacional de Educación para la Justicia Social (RIEJS), 6(1), 77-89. (https://doi.org/10.15366/riejs2017.6.1.004)

Eccles, J. S., \& Gootman, J. A. (Eds.) (2002). Community programs to promote youth development. National Academy Press.

Dessel, A. B., Jacobsen, J., Levy, D. L., McCarty-Caplan, D., Lewis, T. O., \& Kaplan, L. E. (2017). LGBTQ topics and Christianity in social work: Tackling the tough questions. Social Work \& Christianity, $44(1 \& 2), 11-30$. 
Journal of Youth Development | http://jyd.pitt.edu/ | Vol. 16 Issue 5 DOI 10.5195/jyd.2021.1088 Sharing Power in Faith Communities

Garza, P., Artman, S., \& Roehlkepartain, E. C. (2007). Is there common ground? An exploratory study of the interests and needs of community-based and faith-based youth workers. National Collaboration for Youth and Search Institute.

Gates, H. L., Jr. (2021). The Black church: This is our story, this is our song. Penguin.

Grammich, C., Hadaway, K., Houseal, R., Jones, D. E., Krindatch, A., Stanley, R., \& Taylor, R. H. (2010). U.S. religion census: Religious congregations \& membership study. Association of Statisticians of American Religious Bodies.

Greene, K. M., Lee, B., Constance, N., \& Hynes, K. (2013). Examining youth and program predictors of engagement in out-of-school time programs. Journal of youth and adolescence, 42(10), 15571572. (https://doi.org/10.1007/s10964-012-9814-3)

Hernez-Broome, G., \& Hughes, R. J. (2004). Leadership development: Past, present, and future. Human Resource Planning, 271), 24-32.

Khan, L., Hewes, S., \& Ali, R. (2009). Taking the lead: Youth leadership in theory and practice. The Young Foundation. (https://youngfoundation.org/wp-content/uploads/2012/10/Taking-the-LeadOctober-2009.pdf)

Larson, R. W. (2000). Toward a psychology of positive youth development. American Psychologist, 55(1), 170-183. (https://doi.org/10.1037//0003-066x.55.1.170)

Larson, R. W., Hansen, D. M., \& Moneta, G. (2006). Differing profiles of developmental experiences across types of organized youth activities. Developmental Psychology, 42(5), 849-863. (https://doi.org/10.1037/0012-1649.42.5.849)

MacNeil, C. A. (2006). Bridging generations: Applying "adult" leadership theories to youth leadership development. New Directions for Youth Development, 2006(109), 27-43.

Mahoney, J. L., \& Vest, A. E. (2012). The over-scheduling hypothesis revisited: Intensity of organized activity participation during adolescence and young adult outcomes. Journal of Research on Adolescence, 22(3), 409-418.

Marsh, H., \& Kleitman, S. (2002). Extracurricular school activities: The good, the bad, and the nonlinear. Harvard Educational Review, 72(4), 464-515. (https://doi.org/10.17763/haer.72.4.051388703v7v7736)

Mitha, K., \& Adatia, S. (2016). The faith community and mental health resilience amongst Australian Ismaili Muslim youth. Mental Health, Religion \& Culture, 19(2), 192-207. (https://doi.org/10.1080/13674676.2016.1144732)

Mortensen, J., Lichty, L., Foster-Fishman, P., Harfst, S., Hockin, S., Warsinske, K., \& Abdullah, K. (2014). Leadership through a youth lens: Understanding youth conceptualizations of leadership. Journal of Community Psychology, 42(4), 447-462. (https://doi.org/10.1002/jcop.21620) 
Journal of Youth Development | http://jyd.pitt.edu/ | Vol. 16 Issue 5 DOI 10.5195/jyd.2021.1088 Sharing Power in Faith Communities

Noy, C. (2008). Sampling knowledge: The hermeneutics of snowball sampling in qualitative research. International Journal of Social Research Methodology, 11(4), 327-344. (https://doi.org/10.1080/13645570701401305)

Redmond, S., \& Dolan, P. (2016). Towards a conceptual model of youth leadership development. Child \& Family Social Work, 21(3), 261-271. (https://doi.org/10.1111/cfs.12146)

Roehlkepartain, E. C. (2003). Building strengths, deepening faith: Understanding and enhancing youth development in Protestant congregations. In R. M. Lerner, F. Jacobs, \& D. Wertlieb (Eds.). Handbook of applied developmental science. Promoting positive youth and family development (Vol. 3, pp. 515-534). Sage.

Scales, P. C., \& Roehlkepartain, E. C. (2018). The contribution of nonfamily adults to adolescent wellbeing: A global research and policy perspective. In J. E. Lansford \& P. Banati (Eds.), Handbook of adolescent development research and its impact on global policy (pp. 150-170). Oxford University Press. (https://doi.org/10.1093/oso/9780190847128.001.0001)

Sullivan, T. S., Saito, R. N., \& Chamberlain, R. (2018). Youth engagement, voice, and opportunities for decision-making. In P. A. Witt \& L. L Caldwell (Eds.), Youth development principles and practices in out-of-school time settings ( ${ }^{\text {nd }}$ ed.), (pp. 431-461). Sagamore Publishing.

Theriault, D. (2018). A socio-historical overview of Black youth development in the United States for leisure studies. International Journal of the Sociology of Leisure, 1, 197-213. (https://doi.org/10.1007/s41978-018-0013-y)

Yohalem, N., \& Martin, S. (2007). Building the evidence base for youth engagement: Reflections on youth and democracy. Journal of Community Psychology, 35(6), 807-810.

(https://doi.org/10.1002/jcop.20180) 